\title{
Childhood Vaccine Beliefs Reported by Somali and Non-Somali Parents
}

\author{
Emily R. Wolff, MS4, and Diane J. Madlon-Kay, MD, MS
}

Background: In 2011, an outbreak of measles in Minnesota was traced back to an unvaccinated Somali child. The purpose of this project was to (1) ascertain whether Somali parents are more likely than non-Somalis to refuse childhood vaccinations, particularly the measles-mumps-rubella (MMR) vaccine and (2) determine what factors influence the decision not to vaccinate.

Methods: We explored parental perceptions and utilization of vaccines through a survey distributed to a convenience sample of Somali and non-Somali parents of children $\leq 5$ years old in a family medicine clinic in Minneapolis, MN.

Results: A total of 99 surveys were completed, $28 \%(n=27)$ by Somali parents. Somali parents were more likely than non-Somali parents to have refused the MMR vaccine for their child (odds ratio, 4.6; 95\% confidence interval, 1.2-18.0). Most of them refused vaccines because they had heard of adverse effects associated with the vaccine or personally knew someone who suffered an adverse effect. Somali parents were significantly more likely to believe that autism is caused by vaccines (35\% vs. $8 \%$ of nonSomali parents). Somalis were also more likely to be uncomfortable with administering multiple vaccines at one visit (odds ratio, 4.0; 95\% confidence interval, 1.4-11.9) and more likely to believe that children receive too many vaccines.

Conclusions: Statistically significant differences in perceptions and use of vaccines were reported by Somali and non-Somali participants. Somali parents are more likely to believe that the MMR vaccine causes autism and more likely to refuse the MMR vaccine than non-Somali parents. These beliefs have contributed to an immunization gap between Somali and non-Somali children. ( $\mathrm{J}$ Am Board Fam Med 2014;27:458-464.)

Keywords: Autism, Measles, Somalia, Vaccination, Immunization

Measles is one of the most contagious human diseases; approximately 1 in 3000 infected patients die, despite modern medical care. Measles infections account for $50 \%$ of the 1.6 million deaths worldwide each year that are attributed to vaccine-preventable childhood diseases. ${ }^{1}$ Effective vaccination

This article was externally peer reviewed.

Submitted 17 October 2013; revised 15 February 2014; accepted 25 February 2014.

From Department of Family Medicine and Community Health (DJM-K), University of Minnesota Medical School, Minneapolis.

Funding: The study was funded by the David Mercy Summer Externship Program of the Minnesota Academy of Family Physicians Foundation, The Minnesota Academy of Family Physicians, and the American Academy of Family Physicians.

Conflict of interest: none declared.

Corresponding author: Emily R. Wolff, MS4, University of Minnesota Medical School-Twin Cities, 420 Delaware St SE, Minneapolis, MN 55455 (E-mail: smit6761@umn.edu). for measles began in 1963 and led to a dramatic decline in the incidence of measles infections. The disease was declared eliminated from the United States in 2000. Since then, however, measles imported from other countries and low vaccination coverage has continued to put communities at risk. In 2011, 222 cases of measles occurred in the United States-the highest rate of infection in 15 years-most of which were caused by unvaccinated travelers who contracted the disease abroad and returned to spread the infection to unvaccinated contacts. $^{2}$ The largest of the 2011 outbreaks occurred in Minnesota: 21 cases of measles were reported, more than the previous 14 years combined. This outbreak was traced back to an unvaccinated Somali child recently returned to Minnesota from abroad. ${ }^{3}$ Minnesota has the largest Somali population in the United States, estimated at between 25,000 and 40,000 people. $^{4}$ 
Anecdotal evidence suggests that Somalis have expressed serious concerns over the safety of the measles-mumps-rubella (MMR) vaccine. ${ }^{4}$ Previous work in Sweden and the United Kingdom showed that Somali parents are generally positive in their views of vaccines but express serious concern over the MMR vaccine in particular. ${ }^{5,6}$ Autism and the MMR vaccine seem to be closely linked by Somali communities. Not only do Somali parents seem to believe that MMR causes autism, they also believe that autism is more common in their community than among the larger population. ${ }^{4}$ It is thought that these fears have caused a reduction in the number of Somali children in the United States and elsewhere who are vaccinated for MMR. Although the Somali belief that MMR causes autism is widely acknowledged by physicians and public health services and measles outbreaks have been traced back to unvaccinated Somali children, little research has explored Somali vaccination rates, parental decision making regarding the MMR vaccine, or their beliefs about vaccine safety.

The purpose of this project was to ascertain whether Somali parents are indeed less likely than non-Somalis to vaccinate their children for MMR and other diseases. In addition, we wanted to know what factors influence Somali parents' decision not to vaccinate and how they perceive the risks and benefits of vaccinations.

\section{Materials and Methods}

We explored parental perceptions and use of vaccines through a survey distributed to a convenience sample of Somali and non-Somali parents of children $\leq 5$ years old at Smiley's Clinic in Minneapolis, MN. The clinic is a family medicine residency clinic located in a neighborhood with a large Somali population.

We developed a 35-item survey (provided in the Appendix) covering the topics of children's vaccination status, reasons for vaccination compliance/ noncompliance, sources of education/information on health topics, vaccination safety, the MMRautism link, and demographics. The survey was piloted with Somali patients and interpreters to confirm that the survey could be completed in 10 to 15 minutes and that all questions were clear and able to be translated into Somali.

The survey was distributed by the front desk staff. Along with the survey, chocolates were given to all participants as a precompletion incentive. Interpreters were requested to help non-Englishspeaking participants complete the survey and were also given the chocolate incentive to help encourage their assistance. The study was approved by the University of Minnesota Institutional Review Board.

Data were summarized using descriptive statistics. Groups were compared using 2-tailed Fisher exact tests. $P$ values $<.05$ were considered statistically significant, and no adjustments were made for multiple comparisons. Analysis was performed using Microsoft Excel (Microsoft Corp., Redmond, WA) and Epi Info 7 software (Centers for Disease Control and Prevention, Atlanta, GA).

\section{Results}

\section{Demographics}

Approximately 200 surveys were distributed from August 2012 through February 2013; 99 participants returned completed surveys. The mean age of participants was 33 years, and $83.3 \%(n=80)$ were female (Table 1). Parents had an overall average of 3 children: Somali parents had a mean of 3.76 children (range, 1-9 children) and non-Somali parents had 2.57 children (range, 1-12 children). Slightly more than one third of participants $(37.6 \%)$ had a high school education or less, and no significant educational differences were found between Somali and non-Somali parents. Of participants, 58.8\% were born in the United States. The participating patient population was fairly representative of the Smiley's Clinic patient demographics: $28.1 \%$ Somali, $27.8 \%$ non-Hispanic white, $19.8 \%$ non-

Table 1. Demographics of Parents Completing the Written Survey

\begin{tabular}{|c|c|c|c|}
\hline Demographics & $\begin{array}{c}\text { Total } \\
(\mathrm{n}=99)\end{array}$ & $\begin{array}{c}\text { Somali } \\
(\mathrm{n}=27)\end{array}$ & $\begin{array}{l}\text { Non-Somali } \\
\quad(n=69)\end{array}$ \\
\hline Mean age (years) & $33.0(8.4)$ & $31.4(6.4)$ & $33.2(8.7)$ \\
\hline Female & 83.3 & 92.3 & 80.9 \\
\hline $\begin{array}{l}\text { Mean number of } \\
\text { children }\end{array}$ & $3.0(1.9)$ & $3.8(1.9)$ & $2.6(1.8)$ \\
\hline $\begin{array}{l}\text { College education or } \\
\text { higher }\end{array}$ & 34.4 & 26.1 & 38.2 \\
\hline $\begin{array}{l}\text { Mean years in the } \\
\text { United States* }\end{array}$ & $12.6(6.6)$ & $12.1(5.3)$ & $13.7(9.0)$ \\
\hline $\begin{array}{l}\text { Uses interpreter for } \\
\text { clinic visits }\end{array}$ & 15.8 & 53.9 & 1.5 \\
\hline
\end{tabular}

Data are mean (standard deviation) or percentage.

*Applies to those parents who are foreign born. 
Somali black, 15.5\% American Indian, 4.1\% Asian, and $3 \%$ Hispanic.

\section{Vaccine Use}

Somali parents were more likely (22.2\%) than nonSomali parents (5.8\%) to refuse the MMR vaccine for their children (odds ratio, 4.6; 95\% confidence interval, 1.2-18.0). There was no significant difference in the refusal of any other recommended vaccines between Somali and non-Somali parents (Table 2). When asked about reasons for refusing the vaccine, $42.9 \%$ of Somali respondents who refused the vaccine reported personally knowing someone who had suffered adverse effects to the vaccine, and $57.1 \%$ reported hearing about problems with the vaccine. None of the Somali parents indicated that they were concerned about the efficacy of or lack of research into vaccines.

Concern over "vaccine overload" is a commonly cited reason for parental refusal of vaccination. ${ }^{7}$ When asked how many vaccines parents were comfortable with their child receiving in one visit, only $39.6 \%$ of parents reported being comfortable with whatever number their physician recommended. Somali parents were more likely to report being uncomfortable with multiple vaccines during one visit (odds ratio, 4.0; 95\% confidence interval, 1.4-11.9).

\section{Autism and Vaccines}

When asked whether they had heard about the idea that vaccines could cause autism, $61.6 \%$ of participants $(76.9 \%$ of Somalis and $55.0 \%$ of non-Somalis; $P=.06)$ indicated that they were aware of the theory. Interestingly, a variety of vaccines were implicated: $63.9 \%$ of parents indicated they had

Table 2. Vaccines for Children Refused by Parents in a Written Survey

\begin{tabular}{lcrcr}
\hline Vaccine & $\begin{array}{c}\text { Total } \\
(\mathrm{n}=96)\end{array}$ & $\begin{array}{c}\text { Somali } \\
(\mathrm{n}=27)\end{array}$ & $\begin{array}{c}\text { Non-Somali } \\
(\mathrm{n}=69)\end{array}$ & $\begin{array}{c}P \\
\text { Value }\end{array}$ \\
\hline MMR & $10.4(10)$ & $22.2(6)$ & $5.8(4)$ & .03 \\
Hepatitis B & $4.2(4)$ & $0(0)$ & $5.8(4)$ & .57 \\
Varicella & $1.0(1)$ & $0(0)$ & $1.4(1)$ & 1.00 \\
DTaP & $1.0(1)$ & $0(0)$ & $1.4(1)$ & 1.00 \\
Rotavirus & $1.0(1)$ & $0(0)$ & $1.4(1)$ & 1.00 \\
Influenza & $6.3(6)$ & $3.7(1)$ & $7.2(5)$ & 1.00 \\
Other & $1.0(1)$ & $0(0)$ & $1.4(1)$ & 1.00 \\
\hline
\end{tabular}

Data are \% (n).

DTaP, diphtheria-tetanus-acellular pertussis; MMR, measlesmumps-rubella. heard of the MMR vaccine being blamed for autism, but diphtheria-tetanus-acellular pertussis (14.8\%), rotavirus $(8.2 \%)$, hepatitis B $(6.6 \%)$, varicella $(4.9 \%)$ and "other, unknown" (27.9\%) also were mentioned. While both Somali and non-Somali parents had heard of the idea, Somali parents were significantly more likely to believe that vaccines cause autism (35\% vs $8 \% ; P=.02)$. Frequent sources of the idea that vaccines cause autism were friends (29 parents), the Internet (24 parents), and television shows (22 parents).

Slightly more than half of all parents reported knowing a child with autism. Six parents reported having a child with autism, 3 of whom were Somali. Those who indicated that they believed vaccines caused autism were then asked why they held that belief. All Somali parents reported that they held the belief because they knew a child who received the MMR vaccine and then got autism, compared with $40.0 \%$ of non-Somali parents. In addition, $40.0 \%$ of non-Somali parents who believed that vaccines caused autism indicated they held the belief because community members told them that it is true, and $20 \%$ had done research on the topic themselves and believed that science supports the connection.

\section{Vaccines and Society}

Of the participants, 21 parents $(21 \%)-7$ of them from Somalia-had refused a vaccine for their child. Parents who had never refused a vaccine for their child were asked a series of questions regarding their decision to vaccinate. Somali parents were less likely than non-Somalis to indicate approving vaccination because of concern over their child becoming ill $(25.0 \%$ and $62.1 \%$, respectively; $P=$ $.01)$ or disease spreading in the community $(25.0 \%$ and $56.9 \%$, respectively; $P=.02$ ). Both groups were most likely to vaccinate because they trusted their health care provider's judgment $(45.0 \%$ of Somali and $65.5 \%$ of non-Somali participants).

Participants also were asked a series of Likertresponse items regarding broad perceptions of vaccination. The percentages of those who agreed or strongly agreed with each statement are shown in Table 3. The majority of Somali and non-Somali parents agreed/strongly agreed that vaccines are a good way to protect children from disease, that vaccines are very safe, and that every child should receive all recommended vaccines. They were less likely to agree/strongly agree that there was 
Table 3. Percentage of Participants Who Agree or Strongly Agree with Each Statement

\begin{tabular}{|c|c|c|c|c|}
\hline & $\begin{array}{c}\text { Total } \\
(\mathrm{n}=96)\end{array}$ & $\begin{array}{c}\text { Somali } \\
(\mathrm{n}=27)\end{array}$ & $\begin{array}{l}\text { Non-Somali } \\
\quad(\mathrm{n}=69)\end{array}$ & $P$ Value \\
\hline Children get too many vaccines. & 39.4 & 65.4 & 29.4 & .01 \\
\hline Getting vaccines is a good way to protect my child from disease. & 90.4 & 92.8 & 84.0 & .24 \\
\hline There is no proven link between autism and vaccines. & 42.7 & 56.0 & 37.5 & .15 \\
\hline Childhood vaccines are very safe. & 76.3 & 76.0 & 76.5 & 1.00 \\
\hline Every child should get all recommended vaccines. & 79.6 & 88.0 & 76.5 & .26 \\
\hline People should have the right to refuse vaccines for any reason. & 55.6 & 66.7 & 51.5 & .24 \\
\hline Vaccines are given to prevent diseases that are not serious. & 37.4 & 45.8 & 34.3 & .34 \\
\hline
\end{tabular}

no proven link between autism and vaccines, that people should have the right to refuse vaccines for any reason, and that vaccines are given for diseases that are not serious. Somali and nonSomali parents differed significantly in their response to only 1 item: that children get too many vaccines. Somali parents were significantly more likely to agree that children receive too many vaccines $(P=.01): 65.4 \%$ agreed with this statement. However, $88.0 \%$ of Somali parents also agreed that every child should receive all recommended vaccines.

\section{Discussion}

Although most Somali respondents to our survey agreed that childhood immunizations are safe and important to protect children from disease, $35 \%$ of them believe that autism is caused by the MMR vaccine. Somali parents were 4 times more likely than non-Somali parents to report knowing a child who received the MMR vaccine and then was diagnosed with autism. These same concerns about MMR and autism also were found in focus group studies with Somali parents in Sweden and the United Kingdom. ${ }^{5,6}$

It is known that the Somali community in Minnesota believes that their children are more affected by autism than the general public. ${ }^{4}$ A study conducted in 2008 by the Minnesota Department of Health concluded that preschool-aged Somali children were significantly more likely than non-Somali children to participate in the Minneapolis public schools' autism spectrum disorder (ASD)specific special education services. ${ }^{8}$ The difference in the prevalence of Somali and non-Somali children receiving services decreased markedly during the 3 years of study. The report provided no data regarding the actual prevalence of ASD. The Uni- versity of Minnesota recently completed a study that determined that the prevalence of ASD among Somali children in Minneapolis is not significantly different from that of white children, though both Somali and white rates are higher than those of other ethnic groups. ${ }^{\text {? }}$

This study is consistent with reports that Somali parents are more likely than non-Somali parents to refuse the MMR vaccine for their child. Of Somali parents, $22 \%$ indicated that they refused the vaccine. An internal review of 90 Smiley's Clinic charts conducted in 2011 indicated that $71 \%$ of Somali children aged 18 to 36 months received the MMR vaccine compared with $94 \%$ of non-Somali children. 2011 data from Hennepin County, where Minneapolis is located, found that only $57 \%$ of Somali children born in 2009 received the first recommended MMR dose compared with $85 \%$ of non-Somali children. ${ }^{4}$ While Somali children make up only a small proportion of Minnesotan children overall, within the tight-knit Somali community such low immunization coverage presents a serious risk to "herd immunity." Most of the measles cases in Hennepin County during the 2011 outbreak were among Somalis. ${ }^{3}$ Population coverage needs to be $>96 \%$ to prevent outbreaks of measles. $^{10}$

Our survey results are limited by being a convenience sample with a self-selection bias. There were a small number of non-English-speaking participants as well as a small overall sample size, which can lead to type 2 errors. With 6 parents reporting having children with autism, many of these respondents clearly had strong opinions on this topic. Despite these limitations, statistically significant differences in perceptions about and use of vaccines were able to be detected between Somali and non-Somali participants in the survey. 


\section{Future Directions}

The Minnesota Department of Health has in progress several projects regarding autism and the Somali community, in addition to the prevalence study mentioned earlier. ${ }^{8}$ The department has written educational materials about vaccinations and autism that are available in the Somali language. Because many Somalis do not read either English or the written Somali language, the department website also has links to videos about vaccinations and autism in the Somali language with English subtitles.

Although more Somali parents have concerns about MMR and the large number of vaccines, providers also have these conversations with concerned non-Somali parents. The Centers for Disease Control and Prevention, the American Academy of Family Physicians, and the American Academy of Pediatrics have partnered to develop "Providers Resources for Vaccine Conversations with Parents," which are available online (http:// www.cdc.gov/vaccines/hcp/patient-ed/conversations/ index.html). Written information for providers and parents and a video suitable for play in a waiting room also are available on the website. Future research should evaluate the effectiveness of these educational materials on improving vaccination rates.

The authors thank the staff of Smiley's Clinic for their help distributing and collecting the surveys.

\section{References}

1. Sabella C. Measles: not just a childhood rash. Cleve Clin J Med 2010;77:207-13.

2. Centers for Disease Control and Prevention. Measles-United States, 2011. MMWR Morb Mortal Wkly Rep 2012;61:253-7.

3. Centers for Disease Control and Prevention. Measles outbreak-Hennepin County, Minnesota, February-March 2011. MMWR Morb Mortal Wkly Rep 2011;60:421.

4. Rubin R. What's behind the latest measles outbreaks? New York: WebMD; 2011. Available from: http://children.webmd.com/news/20111020/measlesoutbreaks. Accessed January 29, 2014.

5. Kulane A, Johansson A, Robleh I, Bagenholm G. Somali parents' acceptance of MPR vaccination for their children. An exploratory study. Stockholm: Karolinska Institutet; 2007. Available from: www. webbhotell.sll.se/Global/Bhv/Dokument/Rapporter/ MPR-study_Rinkeby.pdf/. Accessed January 29, 2014.

6. Tomlinson N, Redwood S. Health beliefs about preschool immunisations: an exploration of the views of
Somali women resident in the UK. Divers Equal Health Care 2013;10:101-13.

7. Kennedy A, Basket M, Sheedy K. Vaccine attitudes, concerns, and information sources reported by parents of young children: results from the 2009 HealthStyles survey. Pediatrics 2011;127:S92-9.

8. Minnesota Department of Health. Autism and the Somali community-report of study. Available from: http://www.health.state.mn.us/divs/cfh/topic/autism/ somalireport.cfm. Accessed January 29, 2014.

9. Hewitt A, Gulaid A, Hamre K, et al. Minneapolis Somali autism spectrum disorder prevalence project: community report 2013. Minneapolis: University of Minnesota, Institute on Community Integration, Research and Training Center on Community Living; 2013.

10. Poland G. Vaccine and autism: vaccine nihilism and postmodern science. Mayo Clinic Proc 2011;86: 869-71.

\section{Appendix}

\section{Parental Survey on Childbood Vaccination}

1. Do you have a child 5 years old or younger? (Mark one box.)

$\square$ Yes

$$
\text { If } Y \text { es } \rightarrow \boldsymbol{G O} \text { to question } 2
$$

$\square$ No

If $N_{0} \rightarrow$ Thank you for your time. Please STOP now and return this survey to the front desk.

2. Who in your family normally makes the decisions about your child(ren)'s healthcare? (Mark one box.)

\section{$\square$ I do}

$\square$ My spouse does

$\square$ Another family member does

$\square$ The family decides together

$\square$ A non-family member does

3. When you are confused or don't know what to do about your child(ren)'s health, where do you usually go for help? (Mark one box.)
$\square$ A family member
$\square$ A community leader
$\square$ The internet/books
$\square$ My doctor or other health care provider
$\square$ Other

4. What is the most number of vaccine shots you are comfortable with your child(ren) getting in 1 visit? (Mark one box.)
$\square$ None $\square$ 3-4
$\square$ 1-2 $\square 5$ or more

$\square$ Whatever the doctor recommends 
5. Have you refused a vaccine for your child(ren) that a doctor recommended? (Mark one box.)

$\square$ Yes

If Yes $\rightarrow \boldsymbol{G O}$ to question 6

$\square$ No

If $\mathrm{No}_{\mathrm{S}} \rightarrow \boldsymbol{G O}$ to question 9

6. Was the decision to not vaccinate your child(ren) easy to make? (Mark one box.)

$\square$ Yes

$\square$ No

7. Which vaccine did you refuse? (Mark all that apply.)

$\square$ MMR (measles, mumps, rubella)

$\square$ Varicella (chickenpox)

$\square$ Rotavirus

DTaP (diphtheria, tetanus, and pertussis)

$\square$ Hepatitis B

$\square$ Other

8. Why did you refuse the vaccine? (Mark all that apply.)

$\square$ I personally know of someone who experienced a harmful adverse effect.

$\square$ I have read or heard about problems with this vaccine.

$\square$ My insurance does not cover this vaccine.

$\square$ My children are at low risk for this disease(s).

$\square$ The risk for adverse effects from this vaccine is too great.

$\square$ There has not been enough research on this vaccine.

$\square$ I would rather have my child get this disease.

$\square$ This vaccine has not been on the market long enough.

$\square$ I do not think the vaccine is effective in preventing this disease(s).

$\square$ I have moral/ethical/religious concerns regarding this vaccine.

Now GO to question 10.

9. Why did you choose to give your child(ren) all their recommended vaccines? (Mark all that apply.)

$\square$ I trust my health care provider's judgment.

$\square$ My child's school required these vaccines.

$\square$ I want to prevent my child from getting sick.

$\square$ Vaccines help to prevent diseases from spreading in the community.

$\square$ Other
10. What is the most important source of information that has helped you make decisions about your child(ren)'s vaccinations? (Mark one box.) $\checkmark$ A health care provider, such as a doctor or nurse

$\square$ Family

$\square$ Friends

$\square$ Community members

$\square$ American Academy of Pediatrics

$\square$ Centers for Disease Control and Prevention

Internet

Magazines

Television shows

$\square$ Newspapers

$\square$ Radio

$\square$ Other (please specify)

11. Have you ever known someone who was ill from the following diseases? (Mark all that apply.)

$\square$ Measles $\quad \square$ Pertussis (whooping cough)

$\square$ Tetanus $\square$ Varicella (chickenpox)

$\square$ Polio $\quad \square$ Diphtheria

$\square$ Mumps $\quad \square$ Rubella (German measles)

$\square$ I have never known someone with any of these diseases.

12. Have you ever known a child with autism? (Mark all that apply.)

$\square$ Yes, one of my children has autism.

$\square$ Yes, another child I know has autism.

$\square$ No, I have never known a child with autism.

13. Have you heard the idea that vaccines (shots) cause autism? (Mark the one best answer below.)

$\square$ Yes

If Yes $\rightarrow$ Go to question 14

$\square$ No

If $\mathrm{No}_{\mathrm{H}} \rightarrow$ Go to question 18

14. Which vaccines have you heard can cause autism? (Mark all that apply.)

MMR (measles, mumps, rubella)

$\square$ Varicella (chickenpox)

$\square$ Rotavirus

$\square \mathrm{DTaP}$ (diphtheria, tetanus, and pertussis)

$\square$ Hepatitis B

$\square$ Other (please specify)

15. Where did you hear the idea that vaccines cause autism? (Mark all that apply.)

$\square$ A health care provider,

$\square$ Radio such as a doctor or nurse

$\square$ Family $\quad \square$ Friends

$\square$ Community members 
$\square$ Internet $\quad \square$ Magazines

Television shows $\square$ Newspapers

Other (Please specify)

16. Do you believe that vaccines causes autism? (Mark one box.)

$\square$ Yes

If $Y$ es $\rightarrow \boldsymbol{G O}$ to question 17

$\square$ No

$\square$ I don't know

If No or I Don't Know $\rightarrow \boldsymbol{G O}$ to question 18
17. Why do you believe that vaccines causes autism? (Mark one box.)

$\square$ I have known children who received the vaccine and then got autism.

$\square$ My community leaders have told me that its true. $\square$ My family or friends have told me that its true. $\square$ My health care provider told me that its true. $\square$ I have done research on the subject and believe that the science supports the idea.

$\square$ I don't know.

Other (Please specify)

For the next set of questions, mark the box next to each question that best fits your opinion.

\section{Strongly Agree Neutral Disagree Strongly Agree \\ Disagree}

18. Getting vaccines is a good way to protect my child(ren)from disease.

19. I have access to all the information I need to make decisions about vaccines.

20. Childhood vaccines are very safe.

21. Children get too many vaccines.

22. Every child should receive all recommended vaccinations.

23. People should have the right to refuse vaccinations for any reason.

24. It is important to vaccinate people to prevent the spread of disease in my community.

25. Vaccines are given to prevent diseases that are not serious.

26. There is no proven scientific link between childhood vaccines and autism.

Finally, we would like to ask some questions about yourself.

27. What is your race/ethnicity? (Mark all that apply)

$\square$ White

$\square$ Black

$\square$ Hispanic

$\square$ Asian

Other (Please specify)

28. What country were you born in?

$\square$ The United States

If United States $\rightarrow \boldsymbol{G O}$ to question 30 .

$\square$ Somalia

Other (Please specify)

29. How long have you lived in the United States? years
30. Do you use an interpreter when you visit the doctor?

$\square$ Yes

$\square$ No

31. What is your gender?

$\square$ Male

$\square$ Female

32. What is your age? years

33. How many years of education do you have?

$\square$ High school or less

$\square$ Some college

$\square$ College degree or higher

34. How many children do you have? number of children

35. Please use the space below to offer any comments or opinions about childhood vaccinations. 